\title{
Creating Own Histories: Adolescent Girls in Mumbai's Bastis - Use of Photography as a Tool of Documentation and Advocacy
}

Amrita $\mathrm{De}^{+}$

\section{Abstract}

Expressing oneself is a fundamental right as enunciated in many international conventions and national constitutions. Expressing oneself, however, is subject to other factors, namely, one's access to language, and means and platforms of expression. Marginalised groups have historically been kept away from gaining, as well as creating, knowledge and language.

Breaking out of deprivation for marginalised groups requires having a reference framework of their own stories that are accessible to their own people, as well as visible to the rest of the world as legitimate history. As Sheila Rowbotham (1973) says, "in order to create an alternative, an oppressed group must at once shatter the self-reflecting world which encircles it and, at the same time, project its own image onto history.... All revolutionary movements create their own ways of seeing." (p. 27)

This paper seeks to show Vacha's work with adolescent girls who purport to express themselves and document their perspectives through photography. Girls form one of the most marginalised sections of society, due to age and gender. Girls from deprived backgrounds contend with further disabilities of caste and class. Their perspectives are seldom part of the collective consciousness of their own communities, let alone enter mainstream discourses. Vacha uses photography as a useful tool for deprived girls to express and document their stories. Public exhibitions are used to take these images to a wider audience.

Key words: Girls' histories, Photography, Girls' Agency, Advocacy, Vacha, a feminist organisation in Mumbai, India

\footnotetext{
+ Vacha Resource Center for Women and Girls, Mumbai, India, Email: amritaandav@gmail.com C2015 De. This is an Open Access article distributed under the terms of the Creative Commons Attribution License (http://creativecommons.org/licenses/by/2.0), which permits unrestricted use, distribution, and reproduction in any medium, provided the original work is properly cited.
} 


\section{Introduction}

This paper documents how adolescent girls from deprived backgrounds have broken through digital divides of class and gender, and used the medium of photography to express themselves and take their voices to public platforms. The paper looks at how creation of own histories is vital to a marginalised group for empowerment and self-assertion, but that such access to processes of creating history remains out of reach of these groups. Girls, who form one of the most marginalised groups in society, have little access to tools of documentation and self-expression. The paper argues that it is important for them to create their own individual and collective histories, and more importantly, to see themselves as being part of this process, to be able to validate their experiences of being a girl.

The girls, whose experiences this paper includes, are part of the self-expression and leadership programme of Vacha, a feminist organisation in Mumbai, India. The girls are, many a times, lacking in skills of literary and other forms of articulation. This paper states how the medium of photography, in this context, emerged as a useful tool for girls in terms of access, usability, and the respectability and wide reach that this medium gave their voices, especially once the technology was made available to them. The paper documents the process of girls learning to use cameras, and having to deal with class and gender based hostility against their engagement with a public medium like photography. It highlights how public exhibitions of photographs by girls have been effective in creating visibility and awareness about girls' issues and also have been actively used by girls in advocating for their rights.

The first part of the paper explores the need for a marginalised group like girls to create their own histories. This is followed by a discussion of the work done by Vacha with adolescent girls, serving as a background for the emergence of girls extensively using photography for expression and documentation. The next section documents experiences of girls as they learnt photography. The last section explores the effectiveness of photography exhibitions as platforms of discussion and dissent on girls' issues, lending credibility to girls' voices, and facilitating the entry of these voices into public consciousness.

\section{Background}

Women have for long been unrepresented in history, and even if they have, the representation has not been inclusive of all kinds of women. As Mary E. John (2014) says, "'women' constitute a subject prone to marginalisation if not invisibalisation in mainstream historiography and theory" ( $p$. 122). This is especially true for women of marginalised groups such as women of colour, women in India who do not belong to caste ${ }^{1}$ Hindu groups, and girls. Esita Sur (2014) says about the condition of marginality affecting the representation of Muslim women:

...the state of marginality not only constitutes the core of their lived experiences but the very state itself goes through a process of construction involving a wide range of factors and agents in power structures. It becomes possible by constructing a context with deliberation and purpose of creating one's identity. Therefore, the marginal location of Muslim women in our society can also be viewed in the politics of representation of identities and knowledge production (Sur, 2014: 44).

\footnotetext{
1 A social system in India that initially entailed stratification based on sexual division of labour, and was later apparently transformed into an inborn trait (Eriksen, 1995). Commonly referred to as the Varna-jãti system, it is divided into four main hierarchies and many sub-hierarchies - the Brahmins (or the priests) belong to the highest Varna followed by the Khsatriyas (the ruling class and the military elite), the Vaishyas (merchants) and the Shudras (artisans and workers) (Bhattacharyya, 2009; Eriksen, 1995). Outside this Varna-jãti system, there is a socially secluded fifth group (Panchamas) associated mainly with unclean tasks that mainly belong to the Scheduled Castes who are referred to as Dalits (Baruah, 2014). According to the Census of India (2011), Dalits constitute $16.6 \%$ of India's population.
} 
Girls form one of the most marginalised groups in historical representation. They tend to be subsumed either under the category of children, or under women, with little recognition of increasing patriarchal controls on them as they enter adolescence, that are specific to their age and gender. Girls as a group are also not homogeneous, with caste and class creating differing experiences of marginalisation. Girls themselves can best articulate these experiences. However, girls, especially belonging to deprived groups, do not have much access to mediums of expression, nor to processes of knowledge creation. Expression of own experiences by girls, especially on a public platform, is crucial for their authentic representation in history. Gopal Guru (2013) says about the importance of public expression:

...expression in itself may be powerful, but it acquires social power only when it is articulated in public. Expression, in order to become socially relevant if not powerful, has to have a reference point outside itself. This outside is constitutive of an ethically sound social condition. That is to say, those who are speaking or expressing need to have listeners who are ready to listen to even strident or grotesque speech that belongs to the social ecology.... In short, ethics of ears or ethics of listening is a precondition to the right to decent expression. It is here that the freedom of expression becomes a social right. (Guru, 2013: 41)

Thus, the act of expressing oneself, especially on a public forum, is a political act. It is a function of access to language and other forms of expression, of the presence of an audience, and of a history of right to expression itself. This right is seen in modern times as an inherent human right and fundamental part of democratic citizenship, enshrined as it is in various national constitutions including India's, as well as international covenants like the United Nations Universal Declaration of Human Rights, and also for children in the United Nations Convention of Rights of the Child.
However, the exclusionary nature of citizenship (see Menon, 2004) plagues this right as it does other rights too, and the right to expression is periodically denied every time there is any perceived threat to the nation, to 'culture', or to other such concepts used as tools of oppression. While the right to speech and expression is constitutionally protected in India, there are limitations on this right in the form of IPC and $\mathrm{CrPC}^{2}$ codes from the time of colonial rule to ostensibly curb 'hate speech'. These sections, however, have been used often enough to criminalise any expression dissenting from the majoritarian view.

There has historically also been a deeper denial of this right, which is tied to the politics of legitimising certain forms of expression, while other forms are pushed to the margins. Invariably, the latter are forms of expression that have emerged amongst the deprived, either organically and also as a way of protesting the dominantly accepted traditions. Be it the poems that emerged from different Bhakti traditions denouncing hierarchies of caste and gender, subversive songs sung by rural women during weddings slyly protesting against liberties taken by their mothers-in-law, or new forms of writing and language adopted by Dalit ${ }^{3}$ writers more recently, there are many examples of alternate forms of expression used as weapons of protest against social injustice. Nevertheless, there remains the hegemony of forms used by dominant groups over other forms in terms of respectability, acceptance into mainstream culture, usage in formal education and claims to legitimacy.

It is known for use of language that minority language groups often shift to dominant languages as a means of accessing resources, power or participation in the workforce. By shifting to the dominant language, minority

\footnotetext{
2 The IPC, or the Indian Penal Code, is the main code in India covering substantive aspects of criminal law. It spells out most of the offences considered criminal and deserving penal consequences in India. The CrPC, or the Code for Criminal Procedure, lays out the procedural aspect of administration of substantive criminal law in India.

${ }^{3}$ Please refer to footnote 1.
} 
language communities contribute to the total production of a nation at the cost of their language (Sreekumar, 2014). Similarly for expression, traditions used by dominant groups become the most accepted culturally, they become markers of social ascent, coveted by other groups as a way of moving towards the centre of the power structure, and in the process their own traditions of expression move further towards endangerment and extinction.

The denial of expression is a form of social exclusion, as it excludes one from participation in social relations due to discrimination based on their placement in the social hierarchy. As explained by Amartya Sen, being excluded from social relations can be a form of deprivation in itself (constitutive), while also leading to other forms of deprivation (instrumental) ("Reducing Poverty", 2005). Thus being able to express is an act of asserting oneself politically. Expressions when documented, become part of the public domain of knowledge, and when this documentation is of marginalised voices, it is an act of subverting the 'power of expression' (Sreekumar, 2014), which is an exclusionary power dictated by one's placement in the social structures of caste, class and gender. It is a process of creating alternate histories, where the process itself is empowering and liberating, and the creation of the history is vital for the shift of the marginalised away from the margins. It is crucial to have access to past records of people or of groups similar to us to be able to validate our own experiences. As Cosier (2011) says, "stories define us and help us to become. We know ourselves, and others, through a patchwork of biography, memoir, myth, parable, and prophesy" (p. 44). The need to validate is especially important for marginalised groups. Everyday experiences of oppression, violence and deprivation cannot be articulated as such unless there is a framework and language for the same, which derive from a recorded history of such events. In the lack of such a history, these experiences would remain scattered and individual, and be seen as personal problems, instead of social issues. For example, the girls whose voices this paper documents, have spoken about their experiences of menstruation ${ }^{4}$ as causing feelings of alienation from themselves, from their families and their communities. They have spoken of menstruation as alienating them even from other girls. This is because they had been completely unaware that many other girls were undergoing experiences very similar to their own, because of a lack of exposure to such a collective history of girls' stories of menstruation. It was only when they discussed these stories amongst each other, and when they were exposed to such stories told by other girls, that they realised that their experiences were not as isolating as they thought, but were rather part of a common history. Voices of the oppressed however, tend to be the most under-represented or un-represented in history. Questions of representation here refer to what Anupama Rao (2003) explains as both "a set of political claims from within the discourse of parliamentary democracy, as well as the impossible demand for the "authentic" reproduction of presence" (p. 2). Gopal Guru further says about authentic representation while delineating Dalit women's issues, "Social location which determines the perception of reality is a major factor that make the representation of Dalit women's issues by nonDalit women less valid and less authentic" (as cited in Rao, 2003, p. 81). Representations of an oppressed group would, therefore, be the most authentic if these representations were in their own voices. The documentation of such voices is liberating in itself and an important political tool towards understanding and legitimising what might otherwise remain individual experiences.

Girls' voices are some of the most in danger of being invisibalised. Girls living in urban slums are deemed doubly vulnerable due to marketisation of the urban spaces they inhabit on the one hand, and traditional restrictions

\footnotetext{
${ }^{4}$ There is a large literature worldwide on menstruation as a taboo and related socio-cultural practices (Kumar and Srivastava, 2011; Johnston-Robledo and Chisler, 2013; Oster and Thornton, 2009; 2011). This article is however beyond the scope to discuss the debates of menstruation in detail.
} 
rooted in their rural backgrounds on the other. Both forms of patriarchal control play out on girls' bodies, their mobility, and their access to resources, which includes their access to language and to forms of expression (see Bhattacharyya, 2009; 2013; 2014; Condon, et al., 2007; Vishwanath and Mehrotra, 2007). The need for reference to girls' histories to authenticate their own experiences is especially true for girls from deprived backgrounds, whose understanding of the world are otherwise relegated to the private and away from the mainstream the most, and thus scattered and felt unimportant. They emerge as subjects of study or worse, objects of welfare in the eyes of state policy. We can, for example, look at the health care suggestions in the recent Five Year Plans. The 9th Five Year Plan discusses a strategy for adolescent health care that focuses on reducing early marriage, anaemia, infections and menstrual disorders, and antenatal care for high-risk pregnant girls. There is no discussion of an adolescent girl's health requirements that are not to do with her reproductive issues. In the 10th Plan on the other hand, early marriages and pregnancy before 16 years are seen as negative solely because they have an adverse effect on maternal nutrition, birth weight and offspring mortality (Vol. 2, p. 198). There is no acknowledgement at all of how early marriage and pregnancy may affect a girl's health per se, or her education, or other aspects of her development. It also continues with some welfare measures like making girls recipients of food-grains along with under-nourished pregnant and lactating mothers (Vol. 2, p. 11). The 11th Five Year Plan goes a long way in at least acknowledging patriarchal norms affecting women and girls in various fields, but still does not go beyond schemes like providing iron supplements to adolescent girls and the earlier focus on their reproductive health. It is the 12th Plan that has employed an inclusive language where many areas of development have specifically mentioned girls as requiring focus because of gender inequalities. This plan continues with most of the earlier welfare measures but also does try to see structural inequalities negatively impacting girls' development, such as lack of toilets in schools affecting girls' retention rates (Vol. 3, p. 54), or recognising India's skewed sex ratio as part of a larger intergenerational cycle of multiple deprivations and violence faced by girls and women (Vol. 3, p. 164). Such recent inclusive language is however, rare in state policy, and needs to reflect in ground-level implementation and services.

Girls trying to use their own agency to break out of the cycle of deprivation need a reference framework of girls' perspectives of themselves and of the world. They need to 'see', document these ways of 'seeing', and thus become visible to the world and to self in the way that they identify themselves. Girls associated with Vacha who have participated in documenting their own stories using mostly photographs have said that if people from outside their bastis (slum communities) had come in and documented these stories, the portrayal would have been very different. For example, one girl who has used photography to document her stories, said, "they would have probably taken pictures of colourful things, or things they thought looked pretty in a village. But we might not think of these things as pretty." Another girl said that the 'outsiders' might have taken the exact same photographs as the girls did, but unlike the girls, they would not have known the stories behind those pictures. The girls knew about situations and people because they lived amongst them and the photographs taken by them would therefore have a different character. Other girls said that people from outside simply would not know about many things in their bastis as the girls themselves did. However, the most important thing as the girls said was that, people coming in from outside would most probably not be girls. Therefore, they would not know what the girls termed as 'girls' issues'.

As Sheila Rowbotham (1973) says, "in order to create an alternative, an oppressed group must at once shatter the self-reflecting world which encircles it and, at the same time, project its own image onto history.... All revolutionary 
movements create their own ways of seeing" (p. 27). This is a process that is inaccessible to girls of disadvantaged groups because of their obvious distance from access to resources and to knowledge of 'seeing' and documenting. Yet this process is that much more important for an oppressed group, whose understandings have rarely been part of historical narratives. As is often said for writings by Dalit women, their writing is politically important and historiographically necessary since conventional archives (like newspapers and periodicals) and mainstream historical narratives have refused to record their activities (Anandhi, 2009). While individual men and women come equipped with personal memories as validation checkpoints, the society or group has to rely on its historians (Cullen, 1980). Girls need to become their own historians to legitimise their own experiences and record them for creating a collective memory for themselves.

Writing, or creating, their own histories, presumes an access to the means and the language of historiography which is out of reach of girls, especially from deprived backgrounds. Traditional forms of expression and documentation have remained firmly entrenched in the centre of the mainstream, with whatever little radiating to the outer limits hardly reaching marginalised girls because of the pitfalls of class, gender and age divides. Girls possess neither the equipment, the access to discourses or to institutions that legitimise a particular piece of recording or documentation as acceptable history. Usage of 'modern' technology remains dictated by forces of capitalism, reducing its potential accessibility to those in the margins, but it retains its subversive potential because of the nature of technological expansion, which is relatively more democratic than traditional forms of documentation such as writing. Photography, as a means of expression, and of creating an image of a thing in the collective cultural psyche, is a powerful tool of documentation and representation. Gillian Rose (2014) discusses this is the context of urban photography:
The work of re-presentation always represents both an urban scene but also a social scene, both in what is pictured but also in how it is pictured and what relation is established with specific viewers by the formal components of the image. Many scholarly studies have therefore taken photographs of different urban places and explored how their content and symbolic references affirm or contest other discourses defining the urban. (p. 6)

Photographs thus used by girls to represent themselves can change perspectives about girls and also can change perspectives about them in their particular social and physical settings. In addition, photographs can be easily identified as images that must have originated from the 'real world', and which have the power of communicating, according to Srivatsan (1991):

...many different messages in different dimensions. Most obviously and at an overt level, they communicate the message they are invoked to support (advertisement, news, science, etc.). At another level, they act as evidence, posing as copies of a real scene which was 'snapped up' at an opportune moment by an alert eye. (p. 772)

In other words, the photograph promises to speak the 'truth'. There are different dimensions from which the photograph derives its power of legitimacy. First are the equipment and industries which produce, reproduce and communicate the images, starting from the camera and its manufacturing equipment, to the printing equipment, television and computer systems and their manufacturing industry, to delivery systems like newspaper networks, cinema theatres, satellites, receivers, etc. which disperse the photographic images in the world. The immense money and resources that are invested in these industries makes it possible for photographs to have a very wide reach into all parts of society. Second are industries such as the news industry, science and research, the film industry, and so on, which widely use photographs and the 
discourse of and around photography. The respectability of these industries as conveyors of 'truth' and 'objectivity' confer on the photograph itself an "aura of respectability... infecting the photographic images we perceive with the attributes of truth and authority" (Srivatsan, 1991, p. 773).

These attributes of authority and respectability with which photography renders its subjects, make it an effectual tool of documentation by groups whose expressions are denied legitimacy otherwise. The use of photography for expression and documentation is a skill that girls at Vacha, who are from disadvantaged backgrounds, learn and employ as part of the overall process of voicing themselves.

\section{Vacha's Work with Girls}

Vacha is a women's group that emerged from the women's movement in the 1980s in western India. It started as a library and cultural resource centre for women in Mumbai, and in 1995, it started its work on girlhood issues focusing on concerns faced by girls living in Mumbai's bastis, or poor slum communities. The work expanded to include gendered understandings and interventions in many issues faced by the urban poor, and this meant that boys and young men have been an integral part of the stakeholders that Vacha engages with. The main group, however, that Vacha works with are girls in the second decade of their lives.

Vacha means to speak or express in many Indian languages, and one of the underlying objectives of all its work with adolescents and youth has been for them to be able to voice themselves, and to know how to use this voice to be a part of civil society and engage with the state and dominant groups to realise their rights.

Girls at Vacha learn life skills to be able to 'speak' for themselves instead of others speaking on their behalf. One of these skill-sets is that of documentation and presentation. They document their own stories through different media, and Vacha creates enabling platforms where they can present these voices to an audience, thus facilitating the voices entering into public discourse - such as through book publications, photography exhibitions, seminars, and so on.

Photography is one of the main documentation tools that girls at Vacha use to tell their stories. This medium's legitimising potential on the one hand, and relatively wider and easier reach on the other, makes it an effective means for girls to document and present their voices to the world. In addition, the use of photography in itself is an act of breaking through the class, gender and age divides of access to technology. These girls' gender and class disability has usually rendered them passive subjects of photographers; being behind the lens is empowering, they create images of themselves and the world as they see it, and thus at once transform and expand the epistemology of their world. The public display of their photographs has similar revolutionary capacity of changing the parameters of who can see and who can be seen. Seeing these photographs taken by girls imprints on the viewer's actual images of how girls see the world, and the existence of these photographs in the public eye also assists their entry into vehicles of public discourse like newspapers (such as when photography exhibitions by girls are covered in newspaper articles), reports (such as in project reports written to funders), social media (such as in invites, posts, blogs, etc. on social media sites), and so on.

Photography has over the years become one of the main skills that girls have used to participate in civic life and to advocate for their rights. Such advocacy is at different levels with their families, their communities and also with the local government bodies. They have frequently used public photography exhibitions for this purpose. Many of these exhibitions are held within the basti to reach out to girls' parents, peers, and local authority figures. The exhibitions are also taken to more public and well-known platforms for larger impact. In the period of 2011 to 2014, other than numerous basti level displays, there have been four major exhibitions held in Mumbai and its suburbs, and 
in Thane District, Maharashtra. Of these, one was in collaboration with a college in South Mumbai, one was at a major arts and culture festival in Mumbai, one was organised in a government provided cultural space for children in Thane District, Maharashtra and one was with a trust in Mumbai that conducts educational and other activities for children. Different kinds of audiences were reached out to at these four exhibitions, with varied themes covered.

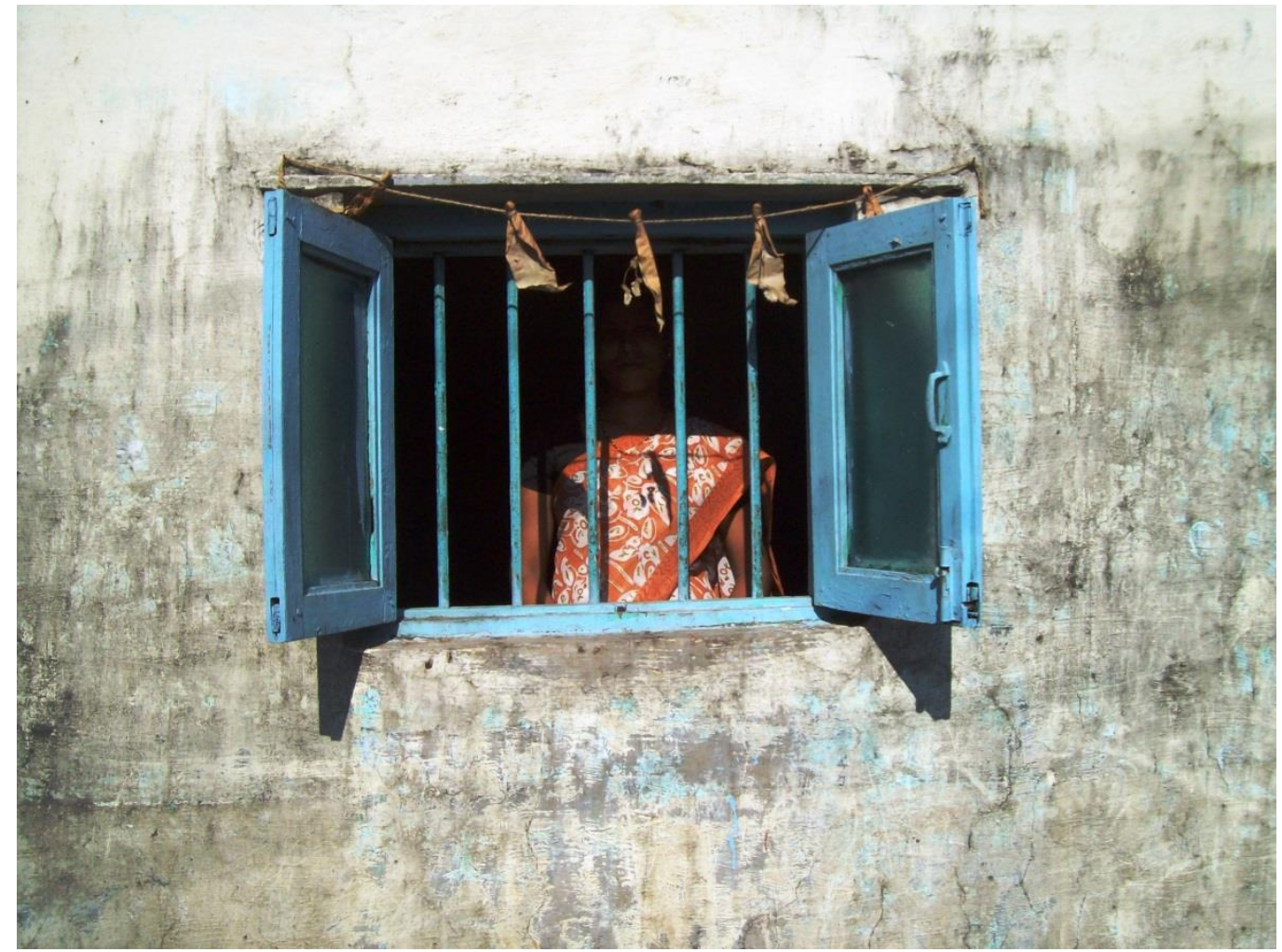

Figure 1: Woman looking through her window. This photograph was taken in Ambernath, Thane District, Maharashtra, 2011. Image (c) Vacha Trust.

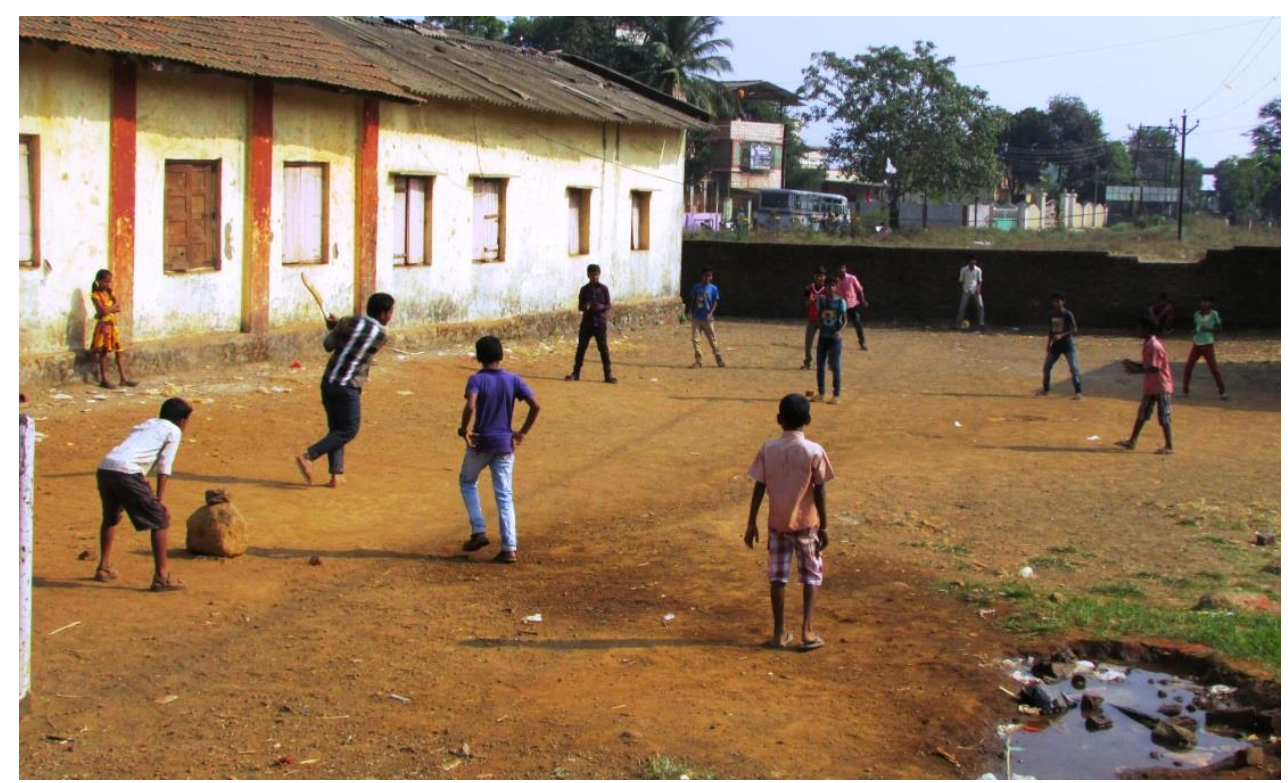

Figure2: A girl watching the boys play. This was taken in Kalyan, Thane District, Maharashtra, 2013. Image () Vacha Trust. 


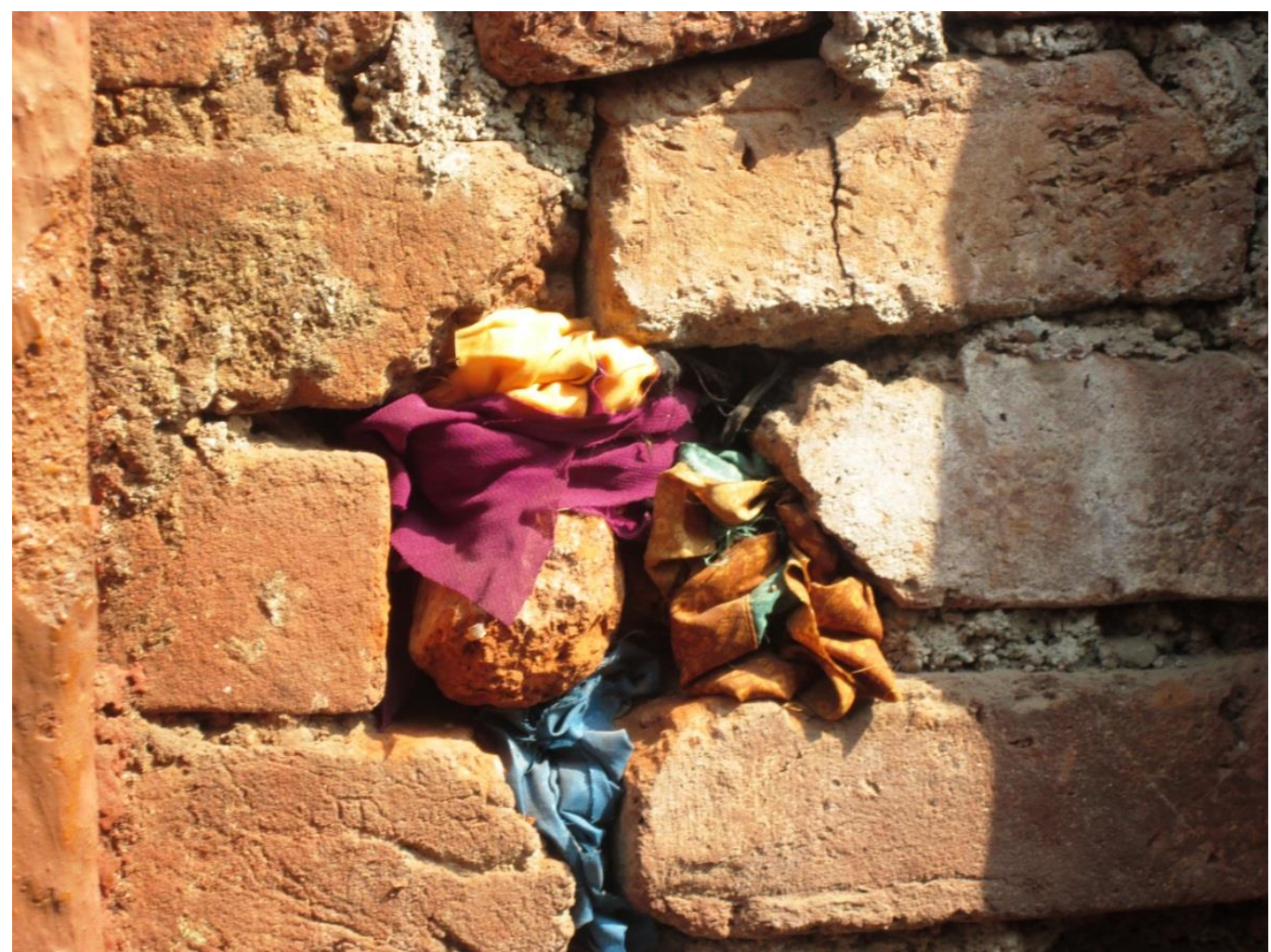

Figure 3: Cloth rags used during menstruation stored by stuffing them in a brick wall. This was taken in Kalyan, Thane District, Maharashtra, 2013, as part of a project where girls were documenting their experiences of menstruation. Image (c) Vacha Trust.

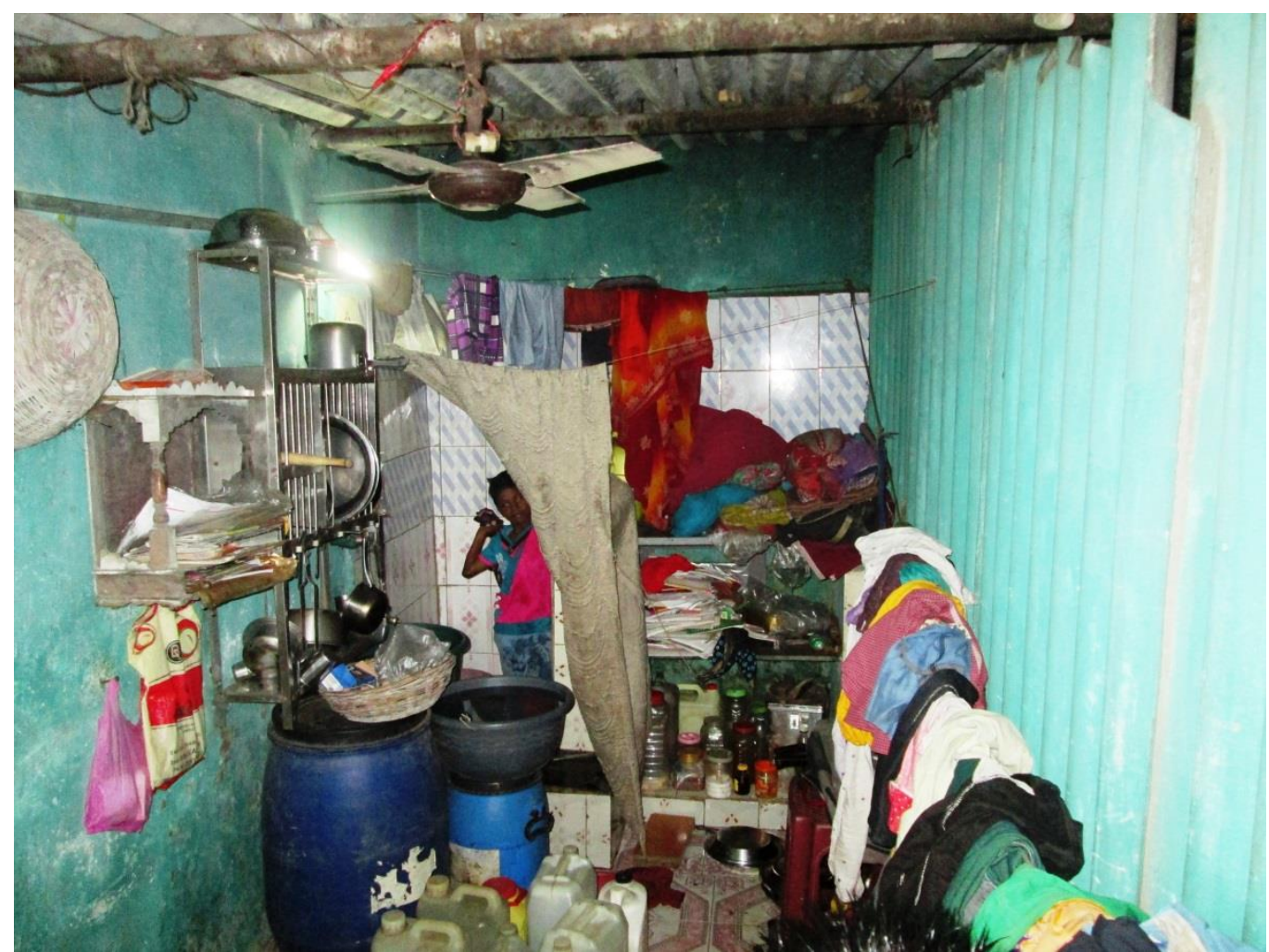

Figure 4: The inside of a regular house in a basti. This was taken in Kalyan, Thane District, Maharashtra, 2014. Image (c) Vacha Trust. 


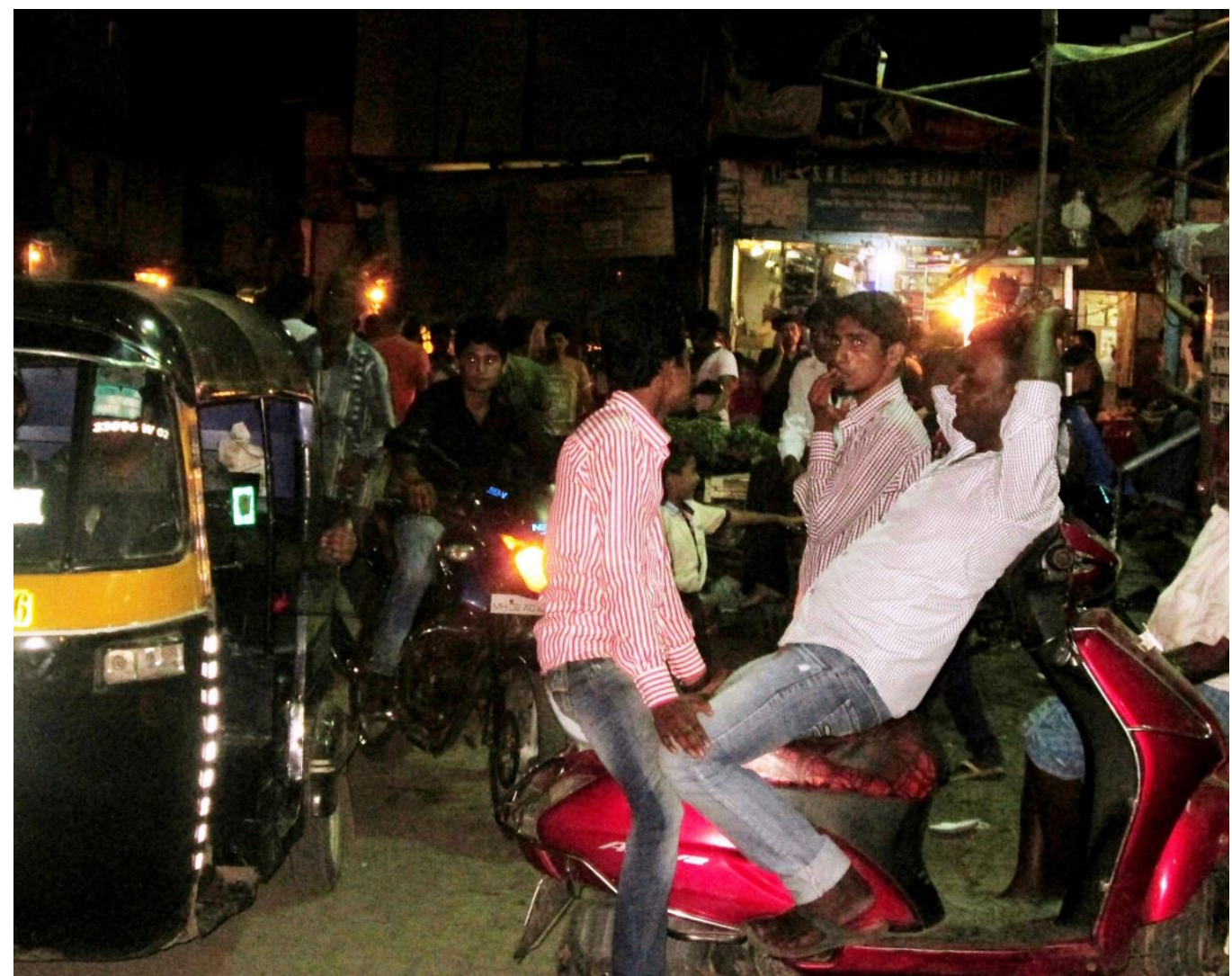

Figure 5: An alley corner in a basti at night. This was taken in Mumbai, 2014, as a part of a project where girls were documenting spaces in the city they feel are unsafe for girls. Image (c) Vacha Trust.

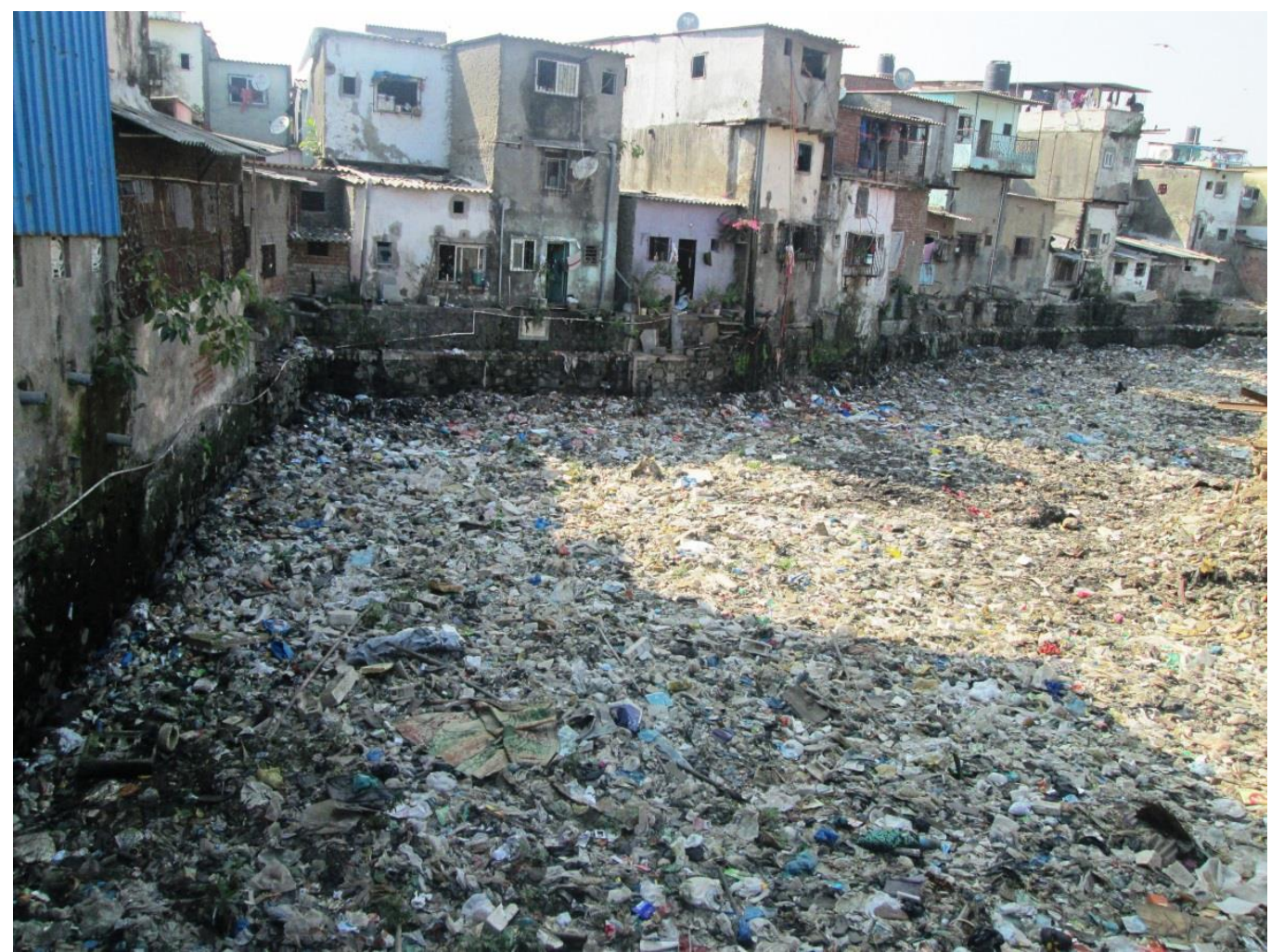

Figure 6: Houses on the banks of a large drain. This was taken in Mumbai, 2014, as part of a drive by girls to document problems of garbage and sanitation issues in their area. Image (c) Vacha Trust. 


\section{About the Girls and Teaching them Photography}

Girls, who participated in the photographytraining, are in the age group of 12 to 18 years, living in poor neighbourhoods in urban and peri-urban areas in Mumbai and Thane in Maharashtra. Many of them have families, which have migrated from different parts of India, mainly north India, to these places for work. Their migrant status places on them the added disadvantage of being 'outsiders', other than already existent disadvantages of gender, class, caste and, sometimes, religion.

Girls in adolescence also face rising restrictions related to age, for this is the age when they are increasingly seen as being in preparation for womanhood. Boys at this age, even if from the same economic class, experience adolescence that is closer to the understanding of adolescence in popular culture; as an age of increasing freedom, exploration, understanding the world and 'growing up'. Girls perhaps experience the last part the most, but the understanding of 'growing up' in their case is much different from the euphemistic chimera of growing up that is usually attributed to adolescence. Girls are seen to be growing up into wifehood and motherhood, and adolescence is the age where they are seen to be entering these stages as they enter puberty. Unlike for boys, when this age and advent into manhood means increasing decision-making and other powers, for girls this age is almost the opposite with growing control over their sexuality and thus, mobility, along with mounting pressures of shouldering household work, as preparation for their roles as wives and mothers. Experiences of girlhood are, therefore, especially crucial to be documented, both for construction of a history of girls' adolescence, which is widely unknown, and also for concretising and thus legitimising girls' experiences as important. Girls' doing this for them makes them a part of this history creation, and gives them tools of analysis for their own situation.
Vacha creates safe spaces of learning for girls within the communities where they live in. This makes it easier for girls to attend Vacha centre, and the process of girls' learning skills and gaining leadership happens within the actual context of their own communities; for girls gaining agency outside of their social ecology is less organic than when this change happens within their communities. In these safe spaces, girls gain skills of expression, documentation, public presentation, group work, negotiation and leadership, as also awareness of self and society, and the platform to express and articulate themselves. They gain an understanding of their rights, and participate in civic life in the form of gathering information about issues in their areas, spreading awareness about solving them and actually working on these issues by engaging with local government and the community. One of these skills is photography. Teaching girls photography has many aspects: it is approached as teaching girls a skill, as giving them a tool of 'seeing' and analysing, as a way of breaking digital divides of gender, age and class, as a medium of bringing about change, and as giving girls the opportunity of gaining authority and visibility in their communities that come with being behind the camera and 'calling the shots'.

Girls attend 2-3 day workshops on photography, which focuses on learning camera handling as well as soft skills. Camera handling includes technicalities of using digital cameras, framing, using light correctly, etc. Soft skills consist of learning about ways of seeing, about using photographs to tell stories, the discipline and patience required to get good photographs, communicating with people and the community while taking photographs, and so on. Girls decide on stories from their own lives or about people or situations they know, which they try to tell through photography. They discuss amongst each other to decide the themes and different aspects of the theme they could cover through photography. This process has enough space for girls to integrate their 
own individual perspectives about a theme, and form collective perceptions. They build their photo essays around these themes, which are then exhibited where the photographer girls are themselves present to explain their views to the audience and hold dialogues with them, using the photographs as starting points of discussion.

Families do not always support the girls to participate in these workshops. First, there is ingrained disbelief and even suspicion about girls using technology. Girls face a lot of discouragement from families and communities about learning and using cameras as many feel that girls cannot be proficient with these technological instruments. These girls are often mocked by brothers and other family members about whether they will be able to handle a camera when they have taken cameras home as a part of their training. One brother told his sisters to give him the camera instead, because he was sure they did not know how to use it, and when they refused, he declared that "you will surely break this camera and then what will your photography teacher say?" In another basti, teachers of a nearby school saw the girls with cameras and told them disparagingly that it was strange that they were being taught photography whereas it should have been the boys learning it.

The discouragement is visible in girls not being allowed to come to the workshops, families not being very serious about the workshops and keeping girls back to finish housework before they go, girls being asked to use the time instead to learn skills such as tailoring, and people in the communities making fun of the girls while they attempt to take photographs.

About the discouragement from families, one girl said later, "My father was quite upset about me learning photography instead of staying at home and doing the housework. He only understood that the photography workshops are about us wasting our time and 'roaming around' with cameras. But I was determined and managed to convince him by saying that I would anyway be doing housework for the rest of the days, but they would just have to adjust for these seven days." Another girl related how her younger siblings, a sister and a brother, rallied around her and helped her complete the photography workshop as they managed their parents back home. Some girls continued to go for their tailoring or beauty parlour classes while also attending the photography workshop. Other girls have said that when they would go out with cameras into their basti, there would be people, especially boys, who would make fun of them by saying things like, "Oh, so you have been given cameras now, but do you even know how to use them?" or, "Beware of these media people! Now that they have cameras they are going to expose all the wrongdoings in this basti". Many girls faced boys leering at them and passing comments, or posing in intimidating ways. Some of these situations have been captured on camera by the girls (Figure 5). Thus, along with a disbelief of girls being able to use the cameras, there was underlying hostility about girls of this socio-economic group having access to cameras, and against the mobility and power that came with engaging in photography. Girls found different ways of dealing with the hostility, with some unexpected results. Gaining confidence to communicate and negotiate in public life is something many girls said they gained. But one of the most common achievements many girls spoke about was gaining the collective power to stand up to sexual harassment from boys, and even gaining their respect once the boys saw that these girls were sincere and good at what they were doing.

\section{Themes Covered and Photography Exhibitions in the Period 2012-2014}

In the period of 2012-2014, photography exhibitions have been used by Vacha as a major platform for adolescent girls to speak out. These exhibitions have been at different levels: bi-annual exhibitions at the basti level for people in the direct ecology of girls, as well as exhibitions held at larger platforms such as college events, seminars and cultural festivals. 
National Seminar on 'Women's Spaces, Women's Voices in Mumbai' (January 2012), Sophia College, Mumbai

A team member of Vacha presented a paper on Girls' Voices and Girls' Spaces: Empowerment Though Expression at a National Seminar on 'Women's Spaces, Women's Voices in Mumbai', held at Sophia College in Mumbai, about the work done at Vacha with adolescent girls to help them gain a voice and speak out through different media. It was an opportune moment for girls' voices to reach the seminar participants and these were presented through an exhibition of photographs taken by girls living in bastis in western suburbs of Mumbai. These photographs were displayed alongside those taken by students and alumni of the Social Communications Media Department, of Sophia Polytechnic, thus giving equal platform to perspectives of girls and young women from two very different social classes. Photographs by Vacha girls at this event were based on life in their bastis, as they wanted to show the world, such as the places where they lived, work they were employed in, and the fun, play and leisure that men, women and children in their bastis engaged in.

Mostly women - professionals from the film and news industry, social media experts, photographers, teachers, activists, and students of Sophia and other colleges, attended the seminar. The juxtaposing of photographs by young women in Mumbai, but from two different social strata, provided a larger canvas for pitching the discussions taking place inside the seminar about there being different and unequal voices from within girls and women. The Vacha photography exhibition had a display of the poem 'And When You Leave, Take Your Pictures with You' by Jo Carrillo (Moraga and Anzaldua: 1983), highlighting the power dynamics photography creates with who has access to the equipment and skills of photography, and who remain subjects. The audience and speakers were mostly from the former category of women, and thus the presence there of photographs by untrained girls from bastis served many purposes: as a point of analysis of multiple girlhoods, as an act of breaking through class barriers, and as a medium for marginalised girls' voices to enter public discourse and be documented in the course of the seminar.

\section{Kala Ghoda Arts Festival (February 2012), Kala Ghoda, Mumbai}

This is a major annual arts and cultural festival in Mumbai. It sees performances of music and theatre, film screenings, art installations, stalls displaying different products - by non-profit organisations and others - of food, handicraft, jewellery, and so on, and also, photography exhibitions.

In the festival in February 2012, Vacha was one of the NGOs to be allocated a wall to display their photographs, as part of an initiative by the Photography Promotion Trust, Mumbai. The photographs were displayed for three days, and viewed by over 2000 people of all ages and social classes.

The audience at this exhibition was varied, and there were Vacha team members and some of the photographer girls themselves were present to explain the presence of these photographs to the viewers. There was the danger of the photos not being taken seriously due to the possible unremarkability of the quality of the photographs in comparison to other artwork in the festival; there was also the larger danger of the photographs being viewed with pity because of the perceived agency-lessness of the photographers. It was crucial at this event for the politics behind the taking and displaying of these photographs to be made clear to the viewers, along with the photographs themselves.

Photographs featured in this exhibition were by girls from two very diverse backgrounds. One group was of girls living in bastis in Mumbai's Western suburbs of Santacruz and Juhu. These girls were mostly either in the last years of school or in college when they had participated in the photography training. Their photographs include images of girls doing various kinds of household chores such as washing clothes, washing utensils, etc. in the narrow lanes 
outside their homes. This is a common sight in bastis, where people, mainly women and girls, do much of the washing right outside their homes, mostly because there is not much space in the tiny washing area within the house, and also because it is easier for the water to drain away directly into the drains running past the houses. One of these photos shows a girl standing with her feet straddling water pipes below while she puts up clothes for drying on a wire fence. Another shows a girl squatting on uneven slabs of concrete while she washes utensils, the water from which falls directly into the open drain below; the girl is thus perched dangerously right above the drain as she washes. There is another series which show women engaged in different kinds of work. A striking picture from this series shows people with large water cans standing in line to fill water from a pipe; a woman stands near the pipe, who is basically the water seller who sells water to each person at a charge. Then there are glimpses of life within the basti showing a child walking a tight rope near the roadside, three small children gleefully looking at a mobile phone screen, a woman hunting for crabs amongst stones at the Juhu beach, the hustle bustle around a stall selling vada paos, which is Mumbai's staple street food, women sitting at the beach and chatting in the evening, a view from above roof tops which show saffron flags above one section of houses, green flags above another, and buildings beyond the basti, and another that shows two bastis divided by a vast drain full of garbage that is large enough for people to cross it using a raft and a stick!

The other group of girls was from a children's home in Ambernath in Thane District near Mumbai. The children's home is situated in a village that is in transition towards urbanisation, and the photographs reflect this. There are different images of women at work of women carrying head loads of cow dung cakes and straw, as also of women going to work in the nearby factories. The landscape is seen to be changing too, with factories, mobile towers, and big cars existing in the same area as kaccha (unmetalled) roads, streams, lakes and vast fields.

Many of the photographs in this exhibition do show filth and deprivation, but not debilitation. Since the photographers are telling their own stories, the images are imbued with agency. The perspective is not that of 'looking into' poverty, but that of poverty speaking from its own standpoint.

\section{Anand Bal Bhavan (January 2014, and December 2014), Dombivali, Thane District}

The photographers here were girls living in villages near Dombivali in Thane District, Maharashtra. The issues taken up by the girls here were similar to those raised by girls in Mumbai, such as restrictions on girls' mobility, on their playing outdoor sports in public playgrounds, fear of girls and women for their safety in public spaces and so on. The contexts were a little different as the spaces that these girls inhabited had traces of the rural left as these villages are still in transition towards urbanisation. Sights captured in the photographs had slightly different nuances because of the physical differences in the landscape of a slum and a village, but more pronounced were the differences faced by these girls when they were actually using the camera. Technology, like the camera, was even more alien to these girls than to girls living in the city, and learning to handle cameras included being comfortable with the language of technology, which is usually English. The community too did not easily accept girls using cameras, and girls felt this discomfort, which showed in their reluctant photography. Many of the photos show members of the photography-learning group themselves playing out situations that they wished as the ideal. For example, there are images of girls playing in public grounds, flying kites, learning to ride bicycles, and so on, which are outdoor activities they are usually not allowed to partake in once they reach puberty. There are pictures of girls playing with boys, which is frowned upon even more. These were actually activities that girls at Vacha had planned for themselves to counter the restrictions they otherwise face. They 
decided to document these activities and display them in the exhibition as enabling situations that would help them access education and other rights. The photographs have also captured the girls as they moved around their basti with the cameras; these include girls interacting with people and going to spaces they would not usually venture into if they were not in a group and had cameras with them, such as on empty roads, at corners occupied by boys and men, near men's workshops, etc., endowing them with a purpose that made it permissible for them to go these spaces.

The exhibition was constructed around one theme - girls' right to education. The group started with a survey of their village to ask both school going and non-school going girls about what they thought were obstacles in their access to education. They also held focus group discussions with a smaller group of girls to further discuss on these issues. Using photography to document these voices was thus one of the steps that girls took to understand and start talking about the situation. The photographs range from showing the condition of women's community toilets and presence of boys on roads, which act as deterrents to girls' movements outside the house, to no presence of girls on playgrounds. The photographers have thus understood girls' mobility and playing in the outdoors as integral parts of them accessing education. The girls did not stop at obstacles to girls' access to education, but also documented boys working at stalls and selling newspapers as barriers to boys' education too.

\section{Balkan Ji Bari (July 2014), Santacruz, Mumbai}

This exhibition was around one theme - spaces in the city that girls feel are unsafe. The photographers were girls who were part of a series of activities where they created awareness and gathered support of people and elected leaders for creating safe spaces for girls in their bastis. The photography exhibition was one event of this series.

The act of taking up cameras, collectively physically being at spaces perceived as unsafe by girls, and 'capturing' these spaces on camera was in itself an act of breaking through the lack of safety at these places.

Girls went in groups to get over their real fear of going to these unsafe places. Their photographs showed varied spaces and times. There was a series of photos taken in the night time, showing roads, food stalls, market areas, parking places for bikes, alleys and other such places which would not look imposing or unsafe at all in the day time, but which have turned into entirely men's spaces in the night with no women or girls visible at all, which girls have perceived as hostile and therefore, unsafe. There was another series showing different kinds of 'gazes' that girls managed to capture. This has the camera 'looking back' at the men and boys as they look at the girls. The series shows men in various stances, and in different places, swaggering at the camera, which is probably how they were looking at the girls when they were taking the pictures. Girls have captured men's leers, smirks, cat calling, and have also perceived their aggressive postures of sitting, standing and walking, and even sheer numbers of men present in a crowded place as uncomfortable and possibly unsafe for girls and women. There are men lounging at an open ground, a group of auto rickshaw drivers taking a break, boys crowding a narrow alley, and a bunch of young men walking down towards the camera while pulling up their shirt collars; all these men are looking at the girls with what can only be described as the 'male gaze'. These observations match those observed in earlier studies (Bhattacharyya, 2009; 2013; 2014; Vishwanath, K. and Mehrotra, 2007). A third series shows different lonely places, which are many a time, quite innocuous looking, but which girls have perceived as unsafe. These include abandoned warehouses, stretches of wooded or marshy areas behind bastis, a dump yard for old cars, gated grounds, and so on. Lastly, girls had also included a series of pictures showing broken gutters, naked wires, and garbage heaps as places or situations they found as unsafe in their basti. 
While taking photographs of these unsafe places, girls did come across instances of women and girls 'occupying' some public spaces. They captured these moments too, which were included in the exhibition. One of these photos shows a young girl flourishing a bat while standing in front of a gym, a space which is understood to be a men's space and which was the same space where girls photographed a group of boys as the boys leered at them. Another photo shows women and girls enjoying on the beach, while a few show the photographers themselves with their cameras as they move through the spaces, which they have perceived as unsafe.

The audience at this exhibition comprised of large number of students and their teachers from nearby schools and colleges. The photographer girls were themselves present, and the exhibition became a space for the girls to hold dialogues with the male and female students, many of them unbelieving and hostile towards such a theme, about safety for girls in the city. The photographer girls who themselves were 'victims' of lack of unsafety, became active agents who were speaking out about this issue to young people from their own and other economic backgrounds living in the city. The exhibition was covered in two major English newspapers of Mumbai, which reached one of the bastis, where the photographers lived and had taken the photographs in. There was some backlash against the girls from the community due to one of the photographs published in a newspaper, which showed boys sitting on bikes parked in front of the women's toilet. The parents and friends of these boys threatened and tried to intimidate the girls for daring to speak against their sons. All the threats mostly took on the shape of negative sanctions unless the girls restricted their mobility, their access to resources and their 'audacity' to speak. We at Vacha were ourselves concerned with questions of freedom of expression, and ethics of photography where the subject might be an unwilling and even hostile participant. There was also on the other hand, the question of girls using photography to show what they felt was true, and we had expected some sort of backlash from the community as an expected form of negation by the society of marginalised views, or a manifestation of discomfort and fear at seeing hitherto unseen narratives of their own spaces. It was obvious from the form that this backlash took, that it was mostly the latter, and very few, except maybe us at Vacha, were actually concerned about issues of agency of the boys whose photographs had been unwittingly published in the newspaper without their consent.

The threats, however, soon died down due to sustained strategies by Vacha in the community and also because the girls refused to be cowed down. This exhibition was a medium through which girls' stories and perceptions entered public psyche through circulation in the media, and the girls were thus not just participators but initiators of public discourse.

\section{Conclusion}

There had been three primary objectives of the photography training given to girls, and of the exhibitions. Firstly, it was to give girls tools of expression and documentation, to create their own historical frame of reference for their understanding of girlhoods. To a large extent, girls did gain these skills, breaking gender and class divides of technological access in the process. The display of photographs in the exhibitions created at least for the present, a current image of the way girls saw their world. At times, this was literally the 'gazed upon' projecting their image of 'gazing back' at the 'gazers', such as in photographs in the Balkan Ji Bari exhibition in which boys can be seen aggressively leering at the camera. Secondly, the exhibitions aimed to create a platform for girls to articulate themselves, and to legitimate these voices by using the authenticity accorded to them by the medium of the photograph. The exhibitions assured the presence of a varied audience, thus further legitimatising these marginalised voices. Finally, the objective was for the rest of society to see as the girls saw, and perhaps here, there was a disconnect in the sense that many people who attended the seminars and exhibitions were both technology 
literate as well as 'lettered', belonging to advantaged classes, and by their position of power in the hierarchy of who is allowed to express, they continued to look at the photographs as subjects, just as they continued to see the girls, instead of images and image creators with their own agency. The spaces where this actually did happen, where the images were taken seriously as alternate ways of seeing, and as having the power to change perceptions and question status quos, were within marginalised communities of the girls when they were threatened by a few community members due to the newspaper incident. This is the only time when it seemed like girls' voices had been taken seriously, even if negatively, leading to some shift in the way people looked at the girls. Perhaps, more such exhibitions will lead to the normalising of such initiatives, and the photographs will gain a serious voice capable of subverting the dominant perspective.

\section{References}

Anandhi, S. (2009, February). Writing the History of the Invisible, Economic and Political Weekly, 52-53

Baruah, A. (2014). The Prohibition of Employment as Manual Scavengers and their Rehabilitation Act, 2013: A Review, Journal Space and Culture, India, 1(3), 9-17

Bhattacharyya, R. (2014). Understanding the Spatialities of Sexual Assault against Indian Women in India, Journal Gender, Place and Culture, DOI: 10.1080/0966369X.2014.969684

Bhattacharyya, R. (2013). Are We Empowered? Stories of Young Indian Working women, Saarbrücken, Germany: Lap Lambert Academic Publishing, (ISBN: 978-3-659-20580-4)

Bhattacharyya, R. (2009). Examining the Changing Status and Role of Middle Class Assamese Women: Lessons from the Lives of University Students (Doctoral Dissertation), University of Newcastle upon Tyne, United Kingdom. https://theses.ncl.ac.uk/dspace/bitstream/104 43/303/1/Bhattacharyya09.pdf
Condon, S., Lieber, M. and Maillochon, F. (2007). Feeling Unsafe in Public Places: Understanding Women's Fears. Revue Française de Sociologie, 48 (Supplement), 101128. http://www.jstor.org/stable/40217706

Cosier, K. (2011). Girl Stories: On Narrative Constructions of Identity. Visual Arts Research, $37(2), 41-54$

http://www.jstor.org/stable/10.5406/visuartsre se.37.2.0041

Cullen, M. (1980, May). Women, History and Identity. The Maynooth Review / Revieú Mhá Nuad, 6 (1), 65-79

http://www.jstor.org/stable/20556945

Department for International Development. (2005). Reducing Poverty by Tackling Social Exclusion: A DFID Policy Paper. London: DFID Eriksen, T.H. (1995). Small Places, Large Issues: An Introduction to Social and Cultural Anthropology, London: Pluto Press

Guru, G. (2013, March). Freedom of Expression and the Life of the Dalit Mind. Economic and Political Weekly, 48 (10), 39-45

John, M. (2014, May). Feminist Vocabularies in Time and Space - Perspectives from India.

Economic and Political Weekly, 49 (22), 121-130

Johnston-Robledo, I and J. C. Chrisler (2013). The Menstrual Mark: Menstruation as Social Stigma, Sex Roles, 68 (1-2), 9-18

Kumar, A. and K. Srivastava (2011). Cultural and Social Practices Regarding Menstruation among Adolescent Girls, Social Work in Public Health, 26 (6), 594-604

http://dx.doi.org/10.1080/19371918.2010.525 144

Menon, N. (2004). Recovering Subversion: Feminist Politics Beyond the Law. Ranikhet: Permanent Black

Moraga, C. and Anzaldua, G. (1983). This Bridge Called My Back: Writings By Radical Women of Color. New York: Kitchen Table

Oster, E. and R. Thornton (2009). Menstruation and Education in Nepal, Working Paper 14853, National Bureau of Economic Research, available at: 
http://www.nber.org/papers/w14853

(accessed 24 April 2015)

Oster, E. and R. Thornton (2011). Menstuation, Sanitary Products and school Attendance: Evidence from a Randomized Evaluation, American Economic Journal: Applied Economics, 3, 91-100

Planning Commission Government of India. (1998). Ninth Five Year Plan. New Delhi. http://planningcommission.nic.in/plans/planrel /fiveyr/9th/default.htm

Planning Commission Government of India. (2003). Tenth Five Year Plan. New Delhi. http://planningcommission.nic.in/plans/planrel /fiveyr/10th/default.htm

Planning Commission Government of India. (2008). Eleventh Five Year Plan. New Delhi: Oxford University Press http://planningcommission.nic.in/plans/planrel /fiveyr/11th/11default.htm

Planning Commission Government of India. (2013). Twelfth Five Year Plan. New Delhi: SAGE Publications India http://planningcommission.nic.in/plans/planrel /fiveyr/12th/12default.htm

Rao, A. (Ed.). (2003). Gender and Caste. New Delhi: Kali for Women

Rose, G. (2014). Visual Culture, Photography and the Urban: An Interpretive Framework. Space and Culture, India, 5-13 http://spaceandculture.in/index.php/spaceand culture/article/view/92/55

Rowbotham, S. (1973). Woman's

Consciousness, Man's World. New York: Penguin Books

Sreekumar, P. (2014, January). Development with Diversity - Political Philosophy of Language
Endangerment in South Asia. Economic and Political Weekly

Srivatsan, R. (1991, March). Photography and Society: Icon Building in Action. Economic and Political Weekly, 26 (11/12), 771-788.

http://www.jstor.org/stable/4397434

Sur, E. (2014). Revisiting the Marginal Locations of Muslim Women on Various Sites in India. Space and Culture, India, 1(3), 43-52. http://spaceandculture.in/index.php/spaceand culture/article/view/44/pdf_8

Vishwanath, K. and Mehrotra, S. (2007, April 28). 'Shall We Go Out?' Women's Safety in Public Spaces in Delhi. Economic and Political Weekly, 1542-1548

\section{About the Author}

Amrita De has been working in the field of girls' rights for the last 8 years. She currently coordinates programmes for girls' expression and leadership at Vacha Resource Centre for Women and Girls, Mumbai. She also works as a content developer for life skills education of girls and as a trainer for youth in Understanding Gender. She has documented stories of adolescent girls' experiences of menstruation in the 2014 publication by Vacha - Puberty, Poverty and Gender. Amrita has a Masters in Social Work from Tata Institute of Social Sciences, Mumbai, with a specialisation in Women-centred Social Work. Her interest areas include girls' rights, girls' expressions, gender and youth, gender and caste, gender and urban issues and gender and madness.

\section{Acknowledgements}

The author expresses her gratitude to the anonymous reviewers whose comments have helped invaluably in organising this paper and from whom she has learnt a lot about writing. 